\title{
Implementasi Aplikasi Android untuk Meningkatkan Layanan Promosi di Smk Multazam Gisting
}

\author{
Kanti Lestari 1), Ahmad Hilal Yusuf ${ }^{2)}$, Muhamad Muslihudin ${ }^{3)}$, Panji Andika Pratomo ${ }^{4)}$ \\ ${ }^{122) 344)}$ Prodi Sistem Informasi STMIK Pringsewu, Lampung \\ Jl. Wisma Rini No. 09 Pringsewu, Lampung, Indonesia \\ 1) kantilestrai@gmail.com, ${ }^{2)}$ ahmadhilalyusuf160300@gmail.com, ${ }^{3)}$ mmuslihudin415@gmail.com, \\ 4) panjiandhikap@gmail.com
}

\begin{abstract}
Information technology is moving more and more advanced and developing from every era. One of the most widely used systems at this time is cellular phones (smartphones), especially smartphones (Smartphones), one type of smartphone using the Android operating system. To take advantage of existing technology to socialize Vocational School Multazam to the public, then an android-based information application is needed. The purpose of this study is to implement an application system that can display the location and profile of the Multazam Gisting Vocational School. The stages in the data collection method used are the observation stage, the interview stage, and the library stage. The system method used is the waterfall method. To build the application system using the Invertor App. The design of the system uses the design of flowcharts, use case diagrams, class diagrams. Research conducted at the Multazam Gisting Vocational School produced an information application based on Android Multazam Gisting Vocational School. This application is expected to help and facilitate users in finding information on Multazam Gisting Vocational Schools.
\end{abstract}

Keywords - Android Application, Information System, Vocational Multazam Gisting

Intisari - Teknologi informasi bergerak semakin maju dan berkembang dari setiap masanya. Salah satu sistem yang banyak digunakan pada saat ini adalah telepon selular(smartphone) terutama telepon pintar (Smartphone), salah satu jenis smartphone menggunakan sistem operasi android. Untuk memanfaatkan teknologi yang ada saat ini untuk mensosialisasikan SMK Multazam kepada masyarakat, maka dibutuhkan suatu aplikasi informasi berbasis android. Tujuan dari penelitian ini adalah untuk mengimplementasikan sistem aplikasi yang dapat menampilkan lokasi dan profil SMK Multazam Gisting. Tahapan dalam metode pengumpulan data yang digunakan yaitu tahap observasi, tahap wawancara, dan tahap pustaka. Metode pengebangan sistem yang digunakan adalah metode waterfall. Untuk membangun sistem aplikasi tersebut menggunakan App Invertor. Desain sistem tersebut menggunakan perancangan flowchart, use case diagram, class diagram. Penelitian yang dilakukan di SMK Multazam
Gisting menghasilkan suatu aplikasi informasi SMK Multazam Gisting berbasis Android. Aplikasi ini diharapkan dapat membantu dan memudahkan pengguna dalam mencari informasi terhadap SMK Multazam Gisting.

Kata Kunci - Aplikasi Android, Sistem Informasi, SMK Multazam Gisting

\section{PENDAHULUAN}

\section{A. Latar Belakang Masalah}

Teknologi informasi bergerak semakin maju dan berkembang dari setiap masanya, peranan yang sangat penting bagi kehidupan manusia sehingga sangat dibutuhkan dalam menunjang kegiatan seperti berita, iklan lowongan pekerjaan maupun semua sistem sekolah. Salah satu sistem yang sedang banyak digunakan saat ini diantaranya adalah teknologi mobile pada perangkat telepon selular (ponsel) khususnya telepon pintar (smartphone). Smartphone saat ini sedang ramai dipergunakan dikalangan masyarakat umum seperti pelajar dan mahasiswa, salah satu smartphone yang menggunakan sistem operasi adalah android.

Berdasarkan data statistik oleh badan STATISTA, Sistem operasi Android adalah sistem operasi smartphone yang paling banyak digunakan di Indonesia pada tahun 2014. Pada akhir tahun itu, Android menguasai pangsa pasar hampir 60\%, Sedangkan pada akhir tahun 2015, Android naik jumlah penggunanya menjadi $74 \%$. Pada pertengahan tahun 2016, Android masih di atas $77 \%$ namun masih sulit menuju angka $80 \%$. Diperkirakan, pada akhir tahun 2016, 80\% pengguna smartphone di Indonesia menggunakan Android [1].

Selain itu, penelitian yang dilakukan oleh Ari Pambudi [2] tentang Implementasi Model Perangkat Lunak Layanan Informasi Kegiatan Belajar Mengajar Tingkat SLTA 
Dengan Berbasis Operating Sistem Android, Tujuan yang dicapai adalah untuk membantu pihak SLTA dalam mengembangkan pelayanan informasi pengelolaan dan pelayanan system informasi kegiatan belajar mengajar berbasis Android agar dapat memberikan pelayanan secara maksimal dengan dibantu sebuah software. Subjek yang dipilih adalah sekolah yang mengelola dan memberikan pelayanan system informasi kegiatan belajar mengajar dan murid yang memiliki perangkat berbasis Android. Hal ini ditentukan untuk mengetahui preferensi murid dan sekolah dalam pengelolaan dan memberikan pelayanan system informasi kegiatan belajar mengajar masyarakat. Dalam mencapai tujuan tersebut, maka dilakukan analisis terhadap definisi kondisi kegiatan dan prosedur yang berhubungan dengan pengelolaan dan pelayanan system informasi kegiatan belajar mengajar, dan dilakukan pembentukan model dan prototype perangkat lunak untuk perencanaan pengelolaan dan pelayanan system informasi kegiatan belajar mengajar berbasis teknologi informasi untuk sekolah dan murid yang menggunakan perangkat berbasis Sistem Operasi Android. Model ini disimulasikan pelaksanaannya dengan penggunaan perangkat lunak yang ada dan atau pengembangan sistem informasi yang dibutuhkan serta memonitor pelaksanaan prosedur standart yang harus dijalankan setiap kegiatan yang berhubungan dengan Teknologi Informasi [2].

Penelitian yang dilakukan oleh Yazid Achyarudin, dan Abdul Hadi Zulkarnaen [3] tentang Sistem Informasi Akademik Berbasis Android Pada STMIK Global Informatika Multi Data Palembang, Adapun keluaran yang dihasilkan dari pengembangan sistem tersebut adalah aplikasi simpono berbasis Android yang berfungsi sebagai Sistem Informasi Akademik pada STMIK Global Informatika Multidata Palembang. Sedangkan penelitian yang dilakukan oleh Moh. Nasrullah [4] tentang Aplikasi Informasi SMK Kabupaten Pemalang Berbasis Android, menghasilkan aplikasi informasi SMK Kabupaten Pemalang yang dapat menampilkan lokasi sekolah SMK Kabupaten Pemalang yang di akses menggunakan peta google map yang telah dipilih dan profil tentang sekolah yang dipilih. Aplikasi tersebut dibuat dengan menggunakan $P H P$ dan MySQL, Android, Eclipse JUNO, SDK Android 4.2.2 (API 17) dimana android digunakan sebagai launcher dalam menjalankan aplikasi informasi SMK Kabupaten Pemalang berbasis android.

Karena kebutuhan informasi yang tepat sasaran, dimanapun dan kapanpun Aplikasi Android ini cocok untuk di implementasikan dalam proses pelayanan informasi sekolah. Karena tanpa harus menggunakan komputer dan menggunakan internet, cukup menggunakan smartphone untuk mengakses data sekolah yang ada di SMK Multazam Gisting. Sekolah, siswa, dan orang tua tidak perlu kesulitan untuk mengakses data tentang sekolah tersebut.

\section{B. Rumusan Masalah}

Dilihat dari latar belakang masalah di atas dapat disimpulkan bahwa rumusan masalah dari penelitian ini adalah " Bagaimana Memanfaatkan Aplikasi Android Pada Smartphone untuk Pelayanan Informasi Sekolah SMK Multazam Gisting"

\section{Tujuan dan Manfaat Penelitian}

Tujuan dari penelitian ini adalah:

a. Mempermudah Orangtua dan Siswa untuk mengetahui informasi sekolah.

b. Mempersingkat waktu Guru dalam mengakses Informasi sekolah untuk siswa dan orangtua.

c. Dengan pemanfaatan aplikasi android pada smartphone tersebut dapat memberikan kinerja yang lebih baik untuk semua kalangan.

\section{LANDASAN TEORI}

\section{A. Konsep Sistem Informasi}

Menurut Rita Irviani [5] Sistem Informasi dapat didefinisikan sebagai suatu kombinasi teratur dari orangorang, hardware, software, jaringan komunikasi dan sumber daya data yang mengumpulkan, mengubah dan menyebarkan, informasi dalam sebuah organisasi. Kombinasi ini bekerja untuk mendapatkan sebuah informasi untuk mendukung pengambilan suatu kebijakan atau keputusan tertentu [5][6].

Komponen-komponen dari Sistem Informasi adalah:

a. Komponen Input, adalah suatu media yang berfungsi untuk memasukan data dari luar kedalam memori untuk menghasilkan suatu informasi yang dibutuhkan .

b. Komponen Proses, adalah suatu data yang diproses untuk menghasilkan informasi yang diperlukan.

c. Komponen Output, adalah suatu hasil informasi yang berkualitas untuk semua pemakai system.

d. Komponen Kontrol, adalah suatu komponen yang berguna untuk mengendalikan gangguan terhadap Sistem Informasi.

Kelebihan Sistem Informasi salah satu nya adalah sebagai sarana pengambilan keputusan, dengan Sistem Informasi kita dapat mengetahui dampak atau resiko dari keputusan yang kita ambil, baik itu menguntungkan satu pihak maupun kedua belah yang sedang dalam masalah [7].

\section{B. Sekolah Menengah Kejuruan (SMK)}

Pendidikan Menengah Kejuruan adalah pendidikan pada jenjang pendidikan menengah yang memiliki tujuan utama yaitu sebagai pengembangan kemampuan siswa untuk melaksanakan jenis pekerjaan tertentu. Pendidikan Menengah Kejuruan mengutamakan penyiapan siswa untuk memasuki lapangan kerja serta mengembangkan sikap profesional. Sekolah Menengah Kejuruan menyelenggarakan program-program pendidikan yang disesuaikan dengan jenis-jenis lapangan kerja [8]. Sekolah Menengah Kejuruan (SMK) merupakan salah satu bentuk satuan pendidikan formal yang menyelenggarakan pendidikan kejuruan pada jenjang pendidikan menengah sebagai lanjutan dari SMP, MTs, atau bentuk lain yang sederajat. Sekolah dijenjang pendidikan dan jenis kejuruan dapat bernama Sekolah Menengah Kejuruan (SMK) atau Madrasah Aliyah Kejuruan (MAK), atau bentuk lain yang sederajat [9]. 


\section{Android}

Menurut Sri Hartati [10], Android adalah sebuah sistem operasi pada handphone yang bersifat terbuka dan berbasis pada sistem operasi Linux.

Maka dapat disimpulkan bahwa Android merupakan sebuah sistem operasi untuk perangkat mobile berbasis linux yang mencakup sistem operasi, middleware, dan aplikasi. Android menyediakan platform terbuka bagi para pengembang untuk menciptakan aplikasi mereka. Karena perangkat ini membuat hidup kita begitu manis, maka setiap versi Android dinamai dari makanan penutup (dessert) [11].

\section{App Invertor}

App Inventor adalah sebuah aplikasi berbasis web yang dibuat dan dikembangkan oleh Google, dirilis pada 15 Desember 2010, pada awalnya penelitian dilakukan oleh Google dengan tujuan sebagai komputasi pendidikan pada lingkungan pengembangan online. App inventor kini dikembangkan oleh MIT (Massaschusetts Institute of Technology), universitas yang bergerak di bidang teknologi dan diakui di dunia. App Inventor berbentuk aplikasi Web yang memungkinkan pengguna untuk membuat aplikasi yang hebat dan bisa digunakan di telepon selular berbasis android dengan mengerti konsep programming tanpa harus menguasai bahasa pemrograman secara keseluruhan. Intinya App Inventor itu adalah sebuah 'aplikasi' untuk membuat Aplikasi Android bermodalkan browser, semua proyek yang kita buat disimpan secara online yang membantu kita untuk mengembangkannya secara bertahap, tanpa harus melakukan coding, melainkan cukup dengan melakukan drag and drop layaknya kita sedang bermain puzzle [11].

\section{E. Adobe Photoshop}

Adobe Photoshop adalah perangkat lunak editor citra buatan Adobe Systems yang dikhususkan untuk pengeditan foto/gambar dan pembuatan efek. Perangkat lunak ini banyak digunakan oleh fotografer digital dan perusahaan iklan sehingga dianggap sebagai pemimpin pasar (market leader) untuk perangkat lunak pengolah gambar/foto [12].

\section{METODE PENELITIAN}

\section{A. Metode Pengumpulan Data}

Pengumpulan data dilakukan untuk memperoleh suatu informasi dalam sebuah penelitian guna mendapatkan data yang valid. Penelitian ini menggunakan metode sebagai berikut:

\section{a. Tahap Observasi}

Pada tahap ini peneliti melakukan pengamatan terhadap SMK Multazam Gisting yang dalam media sosialisasi nya belum menggunakan Sistem Aplikasi tetapi masih menggunakan media cetak seperti brosur, pamflet, dan lain-lain. Kemudian peneliti akan memecahkan masalah dengan cara Implementasi Aplikasi Android pada SMK Multazam Gisting. b. Tahap Wawancara

Pada tahap ini peneliti melakukan wawancara terhadap Kepala SMK Multazam Gisting, yaitu tentang apa saja yang menjadi kendala pada saat sosialisasi kepada siswa/i SMP/Mts yang akan melanjutkan jenjang pendidikan yang lebih tinggi dan juga kepada masyarakat.

c. Tahap Pustaka

Tahap ini peneliti juga menggunakan metode kepustakaan yang berupa media cetak seperti bukubuku dan internet yang berupa jurnal.

\section{B. Metode Pengembangan Sistem}

Dalam penelitian ini menggunakan metode Waterfall. Yaitu suatu proses dalam pengembangan perangkat lunak secara berurutan, dimana dalam proses pengerjaan nya terus mengalir dari atas kebawah (seperti air terjun) melewati beberapa tahapan yang berurut berupa Requirement (analisis kebutuhan), Design (perancangan dan pemodelan), Implementation (penerapan), Verification (pengujian), dan Maintenance (pemeliharaan).

1) Requirement (analisis kebutuhan)

Langkah ini merupakan analisa terhadap kebutuhan sistem. Peneliti akan menggali informasi sebanyak banyaknya dari pengguna sehingga akan tercipta sebuah aplikasi / program yang bisa melakukan tugas-tugas yang diinginkan oleh pengguna tersebut.

2) Design (Rancangan)

Proses Design akan menterjemahkan syarat kebutuhan ke sebuah perancangan sebuah perangkat lunak yang dapat diperkirakan sebelum diimplementasikan. Proses ini berfokus pada Detail Prosedural (flowchart).

3) Implementation (Penerapan)

Tahapan inilah yang merupakan tahapan secara nyata dalam mengerjakan suatu sistem. Dalam artian penggunaan komputer akan dimaksimalkan dalam tahapan ini. Yaitu tahapan dimana keseluruhan desain diubah menjadi kodekode program. kode program yang dihasilkan masih berupa modul-modul yang selanjutnya akan di integrasikan menjadi sistem yang lengkap untuk meyakinkan bahwa persyaratan perangkat lunak telah dipenuhi.

4) Verification (Pengujian)

Tahapan ini bisa jadi dikatakan sebagai final dalam proses pembuatan sebuah sistem. Yaitu tahap verifikasi oleh pengguna. Pengguna akan menguji apakah aplikasi yang telah dibuat tersebut telah sesuai dengan keinginan pengguna. Tahapan ini adalah final dalam pembuatan program, tapi bukan pada metode pengembangan program.

5) Maintenance (Pemeliharaan)

Tahap akhir dalam pengembangan sistem pada model Waterfall adalah pemeliharaan yang termasuk diantaranya adalah instalasi dan proses perbaikan sistem sesuai dengan keinginan pengguna atau yang sesuai dengan kontrak kerja.

\section{Kerangka Fikir Penelitian}

Berikut ini merupakan alur penelitian yang dimulai dari persiapan dalam menentukan tujuan dari penelitian yang 
dilakukan hingga akhirnya didapatkan hasil yang sesuai dalam penelitian ini.

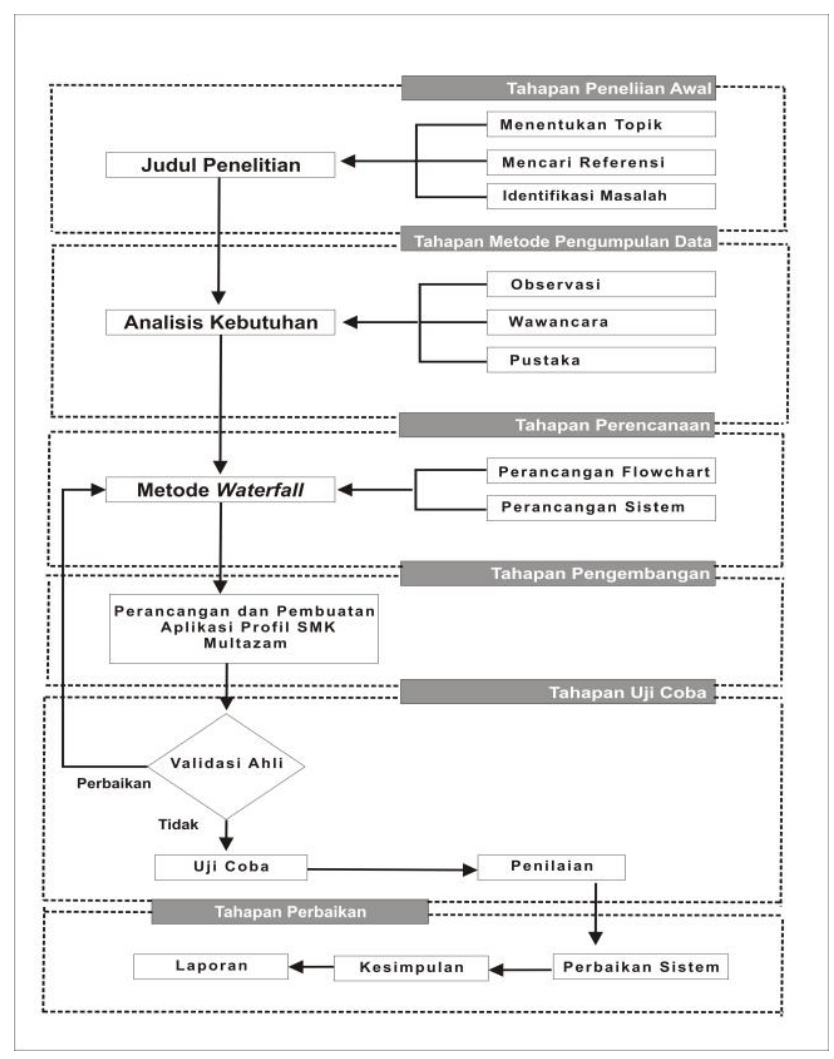

Gambar 3.1. Kerangka Fikir Aplikasi SMK Multazam

Adapun uraian dari kerangka fikir penelitian diatas sebagai berikut :

1. Tahapan Penelitian Awal

Tahap ini merupakan tahapan awal yang terdiri dari menetukan topik dari penelitian tersebut, mencari referensi, dan Identifikasi masalah untuk menentukan judul penelitian.

2. Tahapan Metode Pengumpulan Data

Tahap ini menggunakan metode Observasi, Interview, dan Pustaka dalam menganalisis kebutuhan.

3. Tahapan Perencanaan

Tahap ini melakukan perancangan flowchart dan perancangan sistem untuk memecahkan masalah tersebut secara sistematis agar tersusun secara berurutan dengan menggunakan metode Waterfall.

4. Tahapan Pengembangan

Tahap ini merupakan lanjutan dari tahap perencanaan, yaitu implementasi dengan cara melakukan perancangan dan pembuatan aplikasi profil SMK Multazam.

5. Tahapan Uji Coba

Tahapan berikutnya adalah melakukan uji coba pada sistem tersebut apakah sistem tersebut dapat berjalan sesuai rencana atau tidak.
6. Tahap Perbaikan

Tahapan selanjutnya adalah melakukan perbaikan pada sistem yang telah dibuat agar berjalan sesuai rencana dan dilakukan perawatan dalam sistem tersebut.

\section{PEMBAHASAN}

\section{A. Desain Sistem}

Desain sistem adalah suatu gambaran rancang bangun (blue print) yang lengkap, sebagai penuntun (guideline) bagi programmer dalam membuat aplikasi [13]. Perancangan yang digunakan adalah Flowchart, use case, class diagram.

\section{1) Flowchart}

Flowchart adalah gambar atau bagan yang memperlihatkan urutan dan hubungan antar proses beserta instruksinya.Berikut ini flowchart aplikasi SMK Multazam Gisting.

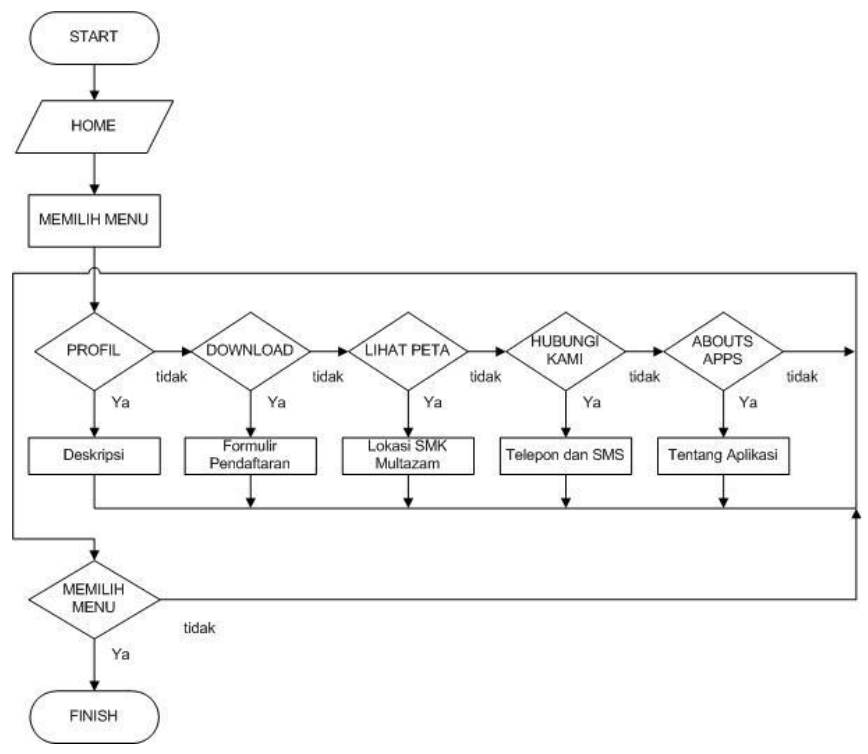

Gambar 4.1. Flowchart aplikasi SMK Multazam

\section{2) Uses Case Diagram}

Uses case diagram adalah suatu urutan atau langkahlangkah yang secara tindakan saling terkait (skenario),baik terotomatisasi maupun secara manual,Use case digambarkan dalam bentuk elips/oval. Berikut use case diagram yang menunjukan aktivitas yang dilakukan oleh pengguna terhadap sistem. 


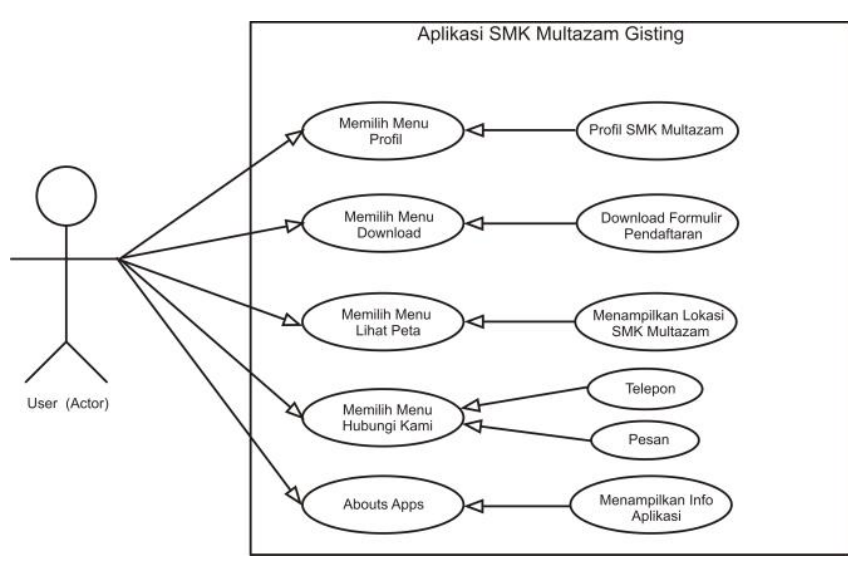

Gambar 4.2. Use Case Diagram aplikasi SMK multazam

\section{3) Class Diagram}

Dari beberapa class yang dihasilkan oleh use case diagram, selanjutnya akan direlasikan kedalam class diagram, sehingga akan diketahui hubungan antara masingmasing komponen. Langkah selanjutnya adalah merancang class diagram yang meliputi:

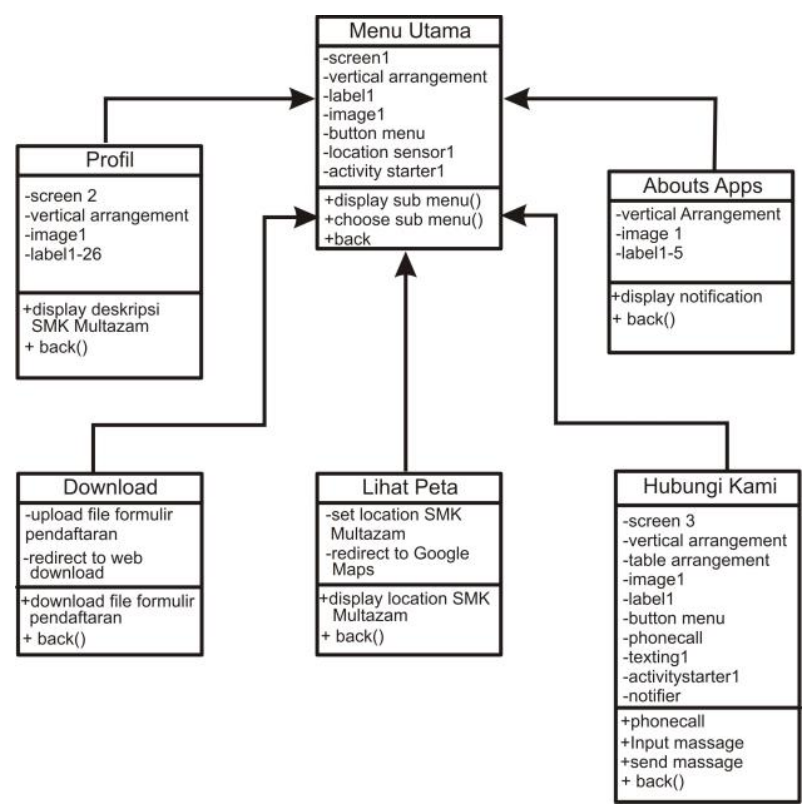

Gambar 4.3. Class Diagram aplikasi SMK Multazam

\section{B. Desain Antarmuka}

Desain antarmuka adalah suatu rancangan atau gambaran suatu sistem yang nantinya akan dibangun. Berikut ini adalah desain antarmuka halaman menu utama.

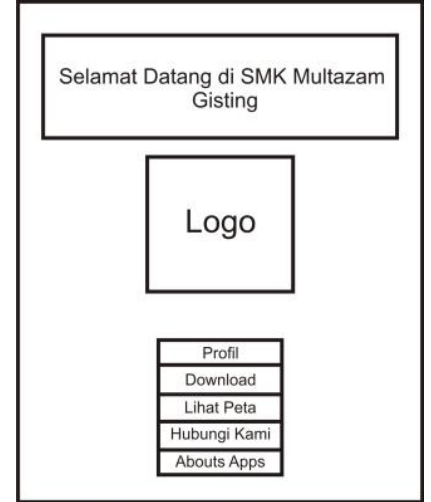

Gambar 4.4. Tampilan halaman menu utama

\section{Implementasi}

Implementasi adalah tampilan dari hasil sistem yang telah dibuat atau dibangun.

\section{1) Halaman menu Utama}

Halaman ini merupakan tampilan awal apliakasi SMK Multazam yang berisi menu piihan. Setiap awal memasuki aplikasi ini, maka akan muncul menu awal ini.

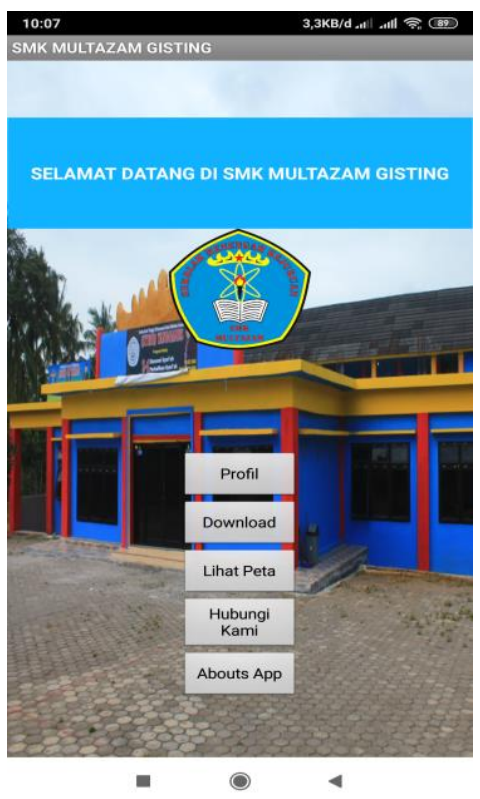

Gambar 4.5. Halaman Menu Utama

\section{2) Halaman Profil}

Menu ini merupakan Profil SMK Multazam Gisting terdiri dari sejarah singkat, visi, misi, tujuan SMK Multazam Gisting. 


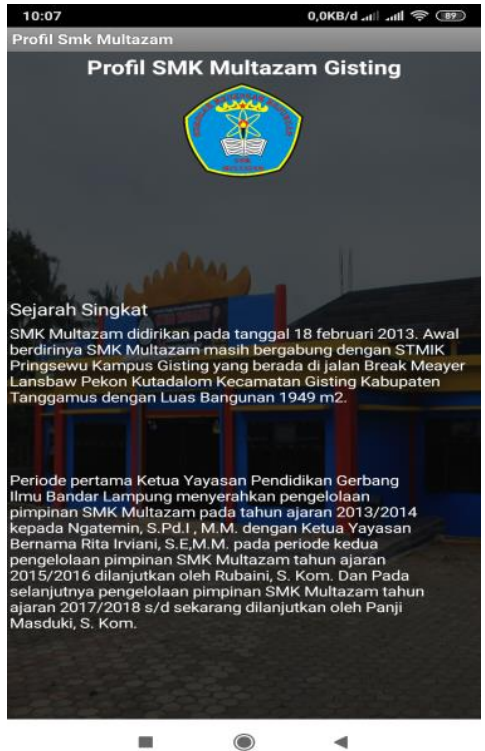

Gambar 4.6. Halaman Profil

\section{3) Halaman Download}

Menu ini merupakan halaman untuk men-download formulir pendaftaran SMK Multazam Gisting, ketika memilih menu tersebut, maka otomatis akan mengarahkan ke situs download yang berisi file formulir tersebut yang siap untuk kita unduh.

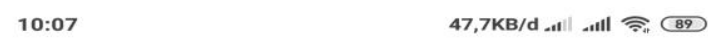

(1) www.mediafire.com/file/oyhda34u01wwamr

Formulir Pendaftaran SMK Multazam.docx

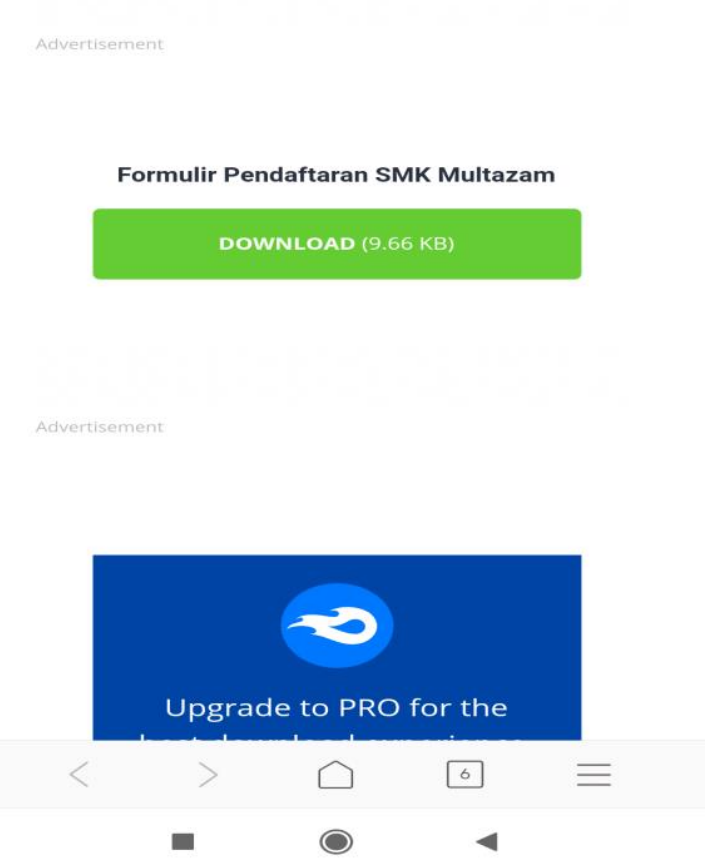

Gambar 4.7. Halaman Download

\section{4) Halaman Lihat Peta}

Menu ini memungkinkan user dapat mengetahui lokasi SMK Multazam Gisting berada secara akurat, seperti menu download tadi, jika kita memilih menu lihat peta maka akan otomatis diarahkan ke google maps.

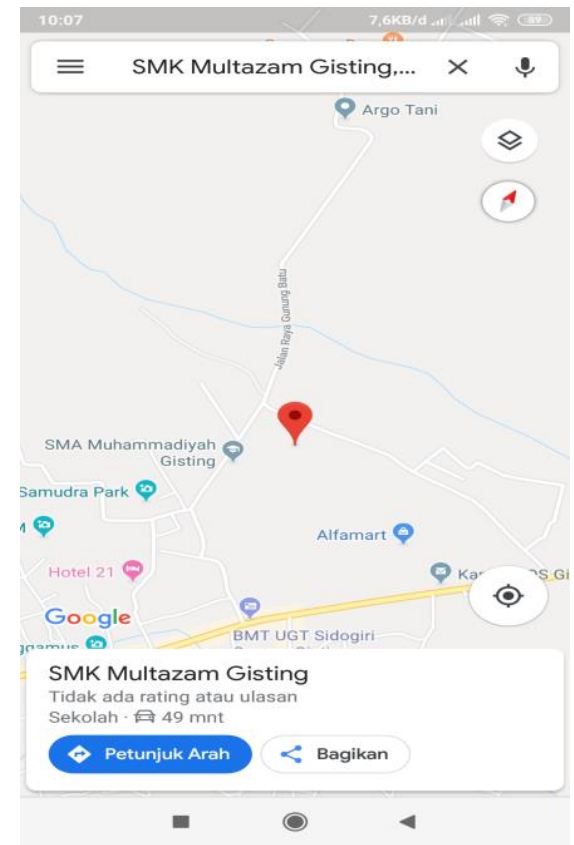

Gambar 4.8. Halaman Lihat Peta

\section{5) Halaman Hubungi Kami}

Menu ini kita dapat menghubungi maupun mengirimkan pesan singkat ke nomor telepon sekolah guna mendapatkan informasi lebih lanjut.

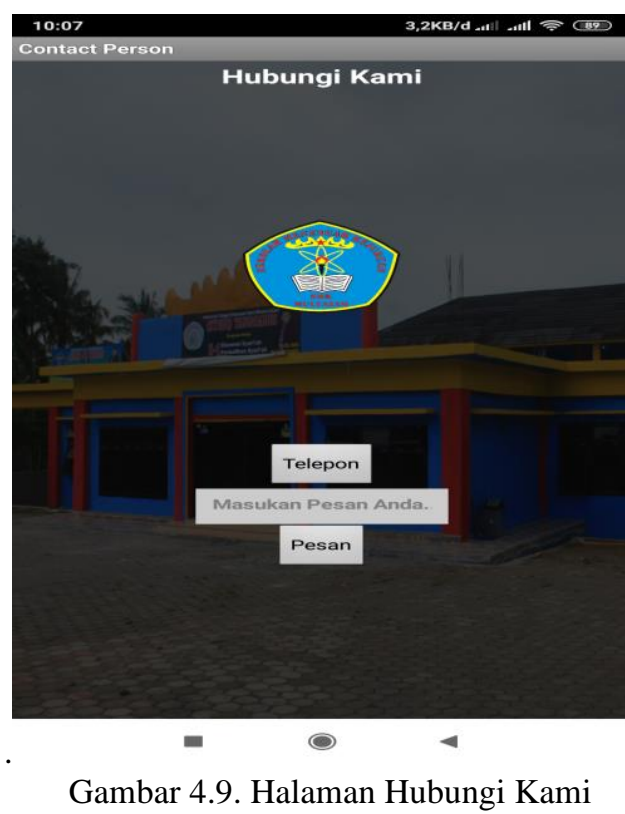

6) Halaman Abouts Apps

Menu ini berisi tentang siapa si pembuat program dan tujuan aplikasi ini dibuat. 


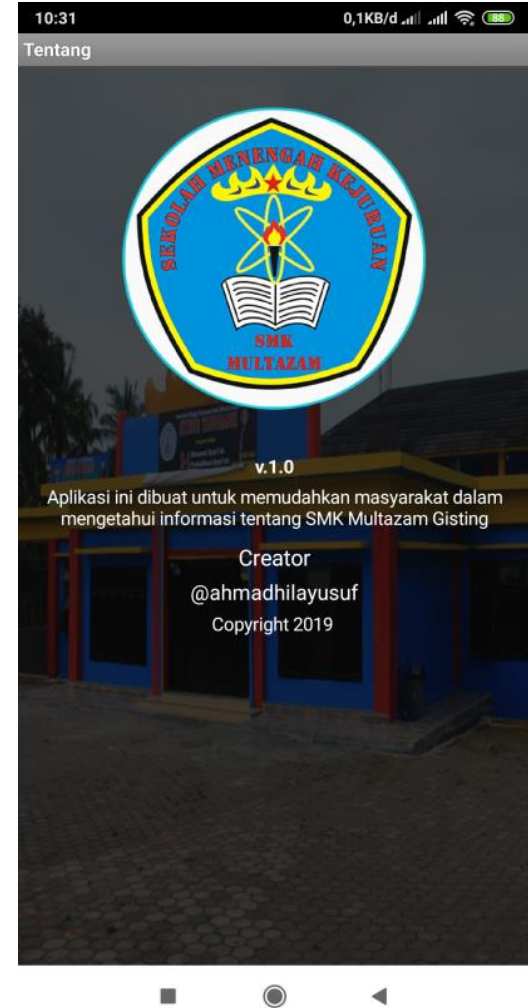

Gambar 4.10 Halaman Abouts Apps

\section{Analisa Hasil Penelitian}

Analisa hasil penelitian adalah hasil dari 10 kuisioner yang telah diberikan kepada 10 responden. Dalam kuisioner yang telah dilakukan oleh penulis dan mendapatkan hasil tentang tampilan dan fungsi dari aplikasi SMK Multazam Gisting yang sudah dibuat. Responden yang menjawab setuju $=68 \%$, tidak setuju $=16 \%$, Sangat Setuju $=16 \%$, dan sangat tidak setuju $=0 \%$. Para responden memberikan jawaban tentang desain tampilannya yang cukup bagus, aplikasi ini mudah digunakan, sama seperti fungsinya, aplikasi ini sangat membantu para user untuk mengetahui profil maupun letak lokasi SMK Multazam Gisting berada.

\section{PENUTUP}

\section{A. Kesimpulan}

Berdasarkan penelitian, analisa, pembahasan, maupun implementasi Aplikasi Android SMK Multazam Gisting, maka didapat kesimpulan sebagai berikut:

1. Dari penelitian ini, telah dihasilkan sebuah aplikasi SMK Multazam Gisting berbasis sistem operasi android yang digunakan untuk memberikan informasi tentang SMK Multazam Gisitng.

2. Pengguna dapat mengetahui lokasi SMK Multazam Gisitng tersebut berada.

3. Pengguna dapat mengunduh formulir pendaftaran yang telah disediakan

\section{B. Saran}

Berdasarkan penelitian, analisa, pembahasan, maupun implementasi Aplikasi Android SMK Multazam Gisting, Aplikasi ini masih jauh dari kata sempurna, yaitu belum adanya sistem admin dalam pelayanannya,seperti download file belum terkoneksi ke database seperti MySql dan sebagainya, maka dari itu disarankan untuk penelitian yang akan datang agar dapat ditambah menjadi apikasi sistem akademik untuk memperbaiki kekurangan yang ada dan semoga dapat menunjang proses belajar menjadi lebih efektif.

\section{REFERENSI}

[1] Era Telematika, "Hampir 80 persen smarthphone di indonesia adalah android. sisanya jadi rebutan 8 vendor," $2016 . \quad$ [Online]. Available: https://www.et.co.id/2016/12/total-pengguna-androidindonesia.html.

[2] A. Pambudi, "Implementasi Model Perangkat Lunak Pelayanan Informasi Kegiatan Belajar Mengajar Tingkat Slta Dengan Berbasis Operating System Android," J. Ilmu Komput., vol. 9, no. 2, hal. 108120, 2013.

[3] Y. Achyarudin, A. H. Zulkarnaen, dan M. Rachmadi, "Sistem Informasi Akademik Berbasis Android Pada STMIK Global Informatika Multi Data Palembang," Sist. Inf. Akad. Berbas. Android Pada Stmik Glob. Inform. Multi Data Palembang, hal. 7, 2013.

[4] M. Nasrullah, "Aplikasi informasi smk kabupaten pemalang berbasis android," no. 5 .

[5] M. M. Rita Irviani, Kasmi, Evi Setyorini, "Perancangan Aplikasi E-Commerce Berbasis Android Pada Kelompok Swadaya Masyarakat Desa Margakaya Pringsewu," J. Ilm. Ilmu Komput., vol. 4, no. 1, hal. 8-12, 2018.

[6] K. P. S. Saputra, Krisna Dwi, "Aplikasi Diagnosa Hama Padi Menggunakan Visual Basic," JTKSI, vol. 01, no. 01, hal. 26-29, 2018.

[7] E. Y. Anggraeni, Pengantar Sistem Informasi. Yogyakarta: CV. ANDI OFFSET, 2017.

[8] Peraturan Pemerintah No 29 Tahun 1990, Pendidikan Menengah. Jakarta, 1990.

[9] Undang-Undang Republik Indonesia Nomor 20 Tahun 2003, Sistem Pendidikan Nasional. Jakarta, 2003.

[10] M. Muslihudin, S. Hartati, N. Setio Budi, D. Puastuti, dan N. A. Kristiana Dewi, "Sistem Aplikasi EDUCHAT STMIK PRINGSEWU Berbasis ANDROID Sebagai Media Komunikasi dan Informasi," J. Teknol. dan Sist. Inf., vol. 3, no. 1, hal. 143, 2017.

[11] E. W. Putra, D. W., Nugroho, A. P., \& Puspitarini, "GAME EDUKASI BERBASIS ANDROID SEBAGAI MEDIA PEMBELAJARAN UNTUK ANAK USIA DINI Dian," J. Inform. Merdeka Pasuruan, vol. 1, 2016.

[12] S. NUR HUMAIDI, H. A. D. Z. I. Q., \& MASITOH, "PENGEMBANGAN BUKU PANDUAN APLIKASI ADOBE PHOTOSHOP CS6 DALAM MENINGKATKAN KETERAMPILAN EDITING FOTO SISWA TUNARUNGU TINGKAT SMALB," 2018.

[13] M. Muslihudin and Oktafianto, Analisis Dan Perancangan Sistem Informasi Menggunakan Model Terstruktur Dan UML. Yogyakarta: Andi Offset, 2016. 